\title{
MEMORIES ARE MADE OF THIS: TEMPORALITY AND PRACTITIONER RESEARCH
}

\author{
Tony Brown and Lorna Roberts, Manchester Metropolitan University.
}

British Educational Research Journal, Dec 2000

\begin{abstract}
This paper sets out to examine the nature of time and how it is constructed within reflective teacher research. The paper is motivated on the one hand by a belief in evolving identity but on the other acknowledges a world where such identities are collapsing into interweaving discourses where notions of such evolution are not tenable. It draws on a classic debate between Gadamer and Habermas concerned with how we experience our living in the present, either as a "being in the world", or, as an "endgainer" aspiring to a new structural framework within which life will be unconstrained by reifications of oppressive relations. After questioning the notion of human agency these views presuppose the paper pursues a resolution offered by Ricoeur and his subsequent work on the close relation between time and the stories we tell about it. Some work arising from a course for teachers is described in which attempts are made to reconcile practice with descriptions of it. In particular, issues of the teachers working with their own earlier writings are discussed. It is suggested that such writings can be used to form a reflective/constructive narrative layer that feeds whilst growing alongside the life it seeks to portray.
\end{abstract}

Stories are precious, indispensable. Everyone must have his history, her narrative. You do not know who you are until you possess the imaginative version of yourself. You almost do not exist without it. (Time Magazine, quoted by Zizek, 1993, p. 11)

“...for nothing is more necessary today than to renounce the arrogance of critique and carry on with patience the endless work of distancing and renewing our historical substance. (Ricoeur, 1981, p. 246).

This paper is concerned with how we might construe time as practitioner researchers. It questions the limits of our capacity to enter into projects of action as intentional beings (Schutz, 1962), trapped as we are in socially derived constructions of the world we experience. It offers alternative versions of how we map out time into the future and how we situate ourselves as beings derived from our pasts. It hints that construing practice as "aiming for an ideal" has a questionable track record. But that we also necessarily experience difficulty in making sense of the present since we understand our present through cultural filters to which we contribute. As researchers this contribution is instilled with our specific research attitude as to whether we see ourselves as "beings in the moment" or as those seeking to achieve a better world at the end of the day. Finally, we turn to see how Ricoeur's work on time and narrative can be applied to some writing produced within a practitioner oriented study. We argue that his emphasis on narrative offers a productive approach to conceiving of reflective writing generated within 
practitioner research as being instrumental in revitalising and renewing the research situation being examined.

\section{The linguistic layer}

Issues of how language is related to the world we experience underpin a substantial part of contemporary philosophy. We restrict ourselves in the first instance to a glance at a particular manifestation of these issues as they have arisen in a dispute between two leading contemporary writers, Gadamer and Habermas.

Gadamer's (1962) analysis sees tradition and language as fundamental constraints to any hermeneutic process. So viewed, the practitioner researcher would be seen as being steeped in tradition and in language which prevent action that can be seen as in any way independent. Yet at the same time the researcher is responsible for constructing this very tradition which constrains him or her. Any creative linguistic offerings a researcher might make are always already partly constituted by virtue of being in an inherited language: "we can only learn about the unknown by recognising it as something already known" (Gallagher, 1992 a, p. 68). We are always immersed in meaning and are unable to enter any situation free of the traditions that gave rise to us. Gadamer firmly asserts the centrality of the individual human in the creation of meaning whilst, on the one hand seeing the world as something of which he or she is part, or, on the other, seeing it as comprising elements upon which he or she can operate. Here learning can be seen as comprising self learning, a learning coming about through experiencing oneself operating on and in the world. In this paradigm, practitioner research would be principally concerned with enabling the researcher to construct meaning. The emphasis would not be on the researcher recreating the reality of the world he or she faces but instead would be on the researcher's production of meaning in respect of his or her given task. The interpretation underlying the research enterprise is seen as producing something new. This Gadamerian stance has been pursued in the field of practitioner research in education by Elliott (e.g. 1987, 1993).

Meanwhile, Habermas's (e.g.1972) analysis aims at unconstrained communication which seeks to avoid reproducing the structures of society and the ideological distortions that go with them. Within such an understanding the task of practitioner research might be seen largely as a transformative process. The scope of Habermas' enquiry extends beyond the universal linguistic dimension which characterises Gadamer's version of interpretation and addresses extra-linguistic factors such as economic status and social class which it sees as distorting interpretations. As in Gadamer's hermeneutics, Habermas' critical social theory presupposes a truth to be found. Habermas' approach has also been pursued explicitly within the domain of practitioner research in education (e.g. Carr \& Kemmis, 1986, Zuber-Skerritt, 1996). Carr and Kemmis, for example, seek to activate movement towards a better situation in which particular conceptions of "educational values" might flourish. In particular, they

(examine) the different views of educational reform implicit in different views of educational research and (defend) the idea that the teacher is a member of a critical community made up of teachers, students, parents and others concerned for the 
development and reform of education. The professional responsibility of the teacher is to offer an approach to this task; to create conditions under which the critical community can be galvanized in to action in support of educational values, to model the review and improvement process, and to organize it so that colleagues, students, parents and others can be actively involved in the development of education. (Carr \& Kemmis, 1986, p. 5, our emphasis)

Here, in line with Habermas, good education seems to be a promise for the future rather than part of a process taking place now.

Ricoeur (1981, p. 78) in comparing Gadamer's and Habermas' arguments suggests that they are premised on different assumptions. Ricoeur suggests that:

1) Habermas' account is based on an overly singular account of history. As such a specific interpretation of the present, and what is wrong with it, is overstated. Gadamer accepted more the inevitability of his own prejudices in creating historical accounts (op cit, pp. 80-81).

2) "Gadamer appeals to the human sciences, which are concerned with contemporary reinterpretation of cultural tradition, (whilst) Habermas makes recourse to the critical social sciences, directly aimed against institutional reifications" (ibid, Ricoeur's emphasis).

3) "(W)hereas Gadamer introduces misunderstanding as the inner obstacle to understanding, Habermas develops a theory of ideology, construed as the systematic distortion of communication by hidden exercise of force" (ibid).

4) For Gadamer the hermeneutic task is based on a "dialogue that we are" (ibid.) whereas Habermas has a quest for "an unrestricted and unconstrained communication that does not precede us but guides us from a future point" (ibid.).

If we take examples of each of these concerns in turn, within the context of practitioner research in education, the difficulty of taking sides is further problematised.

1) As practitioner researchers what assumptions do we make about the situation we are researching? Through what process do we establish the categories through which we organise the questions we choose to ask. For example, Walkerdine (1988) argued that many advocates of Piagetian oriented child-centred learning made particular assumptions about what a "child" was and what needed to be seen as the "natural" way of learning. These assumptions then guided the way in which research was pursued. But how do we understand the creation of these assumptions as being an intrinsic part of a research process evolving through time?

2) As teacher researchers should we focus on the cultural understandings of the subjects we teach or on the way in which these are understood in the specific educational context. For example, within the UK mathematics understood as a traditional discipline is rather different to its reification in the National Curriculum. Where should we begin in delineating our assumptions as to the thing we are researching? 
3) Hermeneutic enquiry, we suggest, is directed at the mutual co-formation of nature and institutions. That is, attempts at describing nature construe subsequent observations. Our attempt to describe the world always results in a formulation that is an approximation to the world being described. The difference between Gadamer and Habermas is whether this formulation should be seen as a misunderstanding or as an ideological distortion. To pursue the example of school mathematics: the attempt to describe mathematics in a curriculum inevitably results in a caricature of traditional understandings of mathematics as a discipline. However, this caricature can be viewed variously, for example, as a serious but imperfect attempt to describe mathematics to guide school instruction or as a cynical ploy to make teachers and children more accountable according to a particular institutionalised account of mathematics or a reconfiguration of the discipline itself to meet contemporary needs. Ricoeur would downplay intent in the construction of the formulation and see it more as a matter of subsequent interpretation, and action on the basis of this, as to whether the formulation was a misunderstanding or an ideological distortion.

4) In Carr and Kemmis' account above (op cit, p. 5) it is assumed that we do not have "the conditions under which critical community can be galvanized in to action in support of educational values". This assumption triggers a particular research orientation. We suggest that Gadamer would have a different attitude as to how the researcher's assumptions trigger and assume a place within a research process. For him, we suggest, the building of the assumptions would be given a higher profile and be seen as integral to the unfolding research enquiry.

A key aspect of this debate for our purposes here is the extent to which one can distance oneself from the use of language one is seeking to reflect on. For Gadamer we are immersed in language and so we cannot assume any distance from language to inspect how it functions. We understand ourselves through the categories of language which simultaneously describe and create the world we inhabit and our relation to this. Within this version of hermeneutics, although we can build a picture of reality, we can never access this reality directly. We always end up describing previous descriptive structurings. For Habermas distortions have occurred in the social fabric which distance language from the reality it seeks or purports to capture. Ricoeur (ibid) is suggesting that resolution of these two perspectives lies in recognising their alternative conceptions of the scope of language. For Gadamer the emphasis is on seeing oneself as part of language where language is all embracing. For Habermas it is possible to distance oneself from language and operate on it to correct its distortions. For the remainder of this paper we develop an account of Ricoeur's alternative course as manifest in his later work and align ourselves with it. This course rests on a more overt account of time in which past, present and future are all understood as being filtered through the medium of narrative. We suggest that this approach reduces the implicit conservativism in the position of Gadamer with its gravitation to existing ways of seeing things. It also avoids Habermas' dual insistence that we work from an assumption of troubled beginnings and that effective action is conditional on getting somewhere first, with the risk of infinite deferral that this implies. We partially accept Elliott's (1993, p. 197) Gadamerian stance in which he suggests that we can be critical of the traditions through which we emerge. Nevertheless, 
whilst the practical reflection Elliott advocates can be seen as a critical instrument, we suggest Ricoeur's analysis offers a radical reconceptualisation of where such critical analysis is centred. In this way Ricoeur supplies a more powerful effacement of the potential dichotomy between the work of Gadamer and Habermas.

\section{Time as narrative}

As researchers, how do we depict the reality we experience? In which senses is this depiction time-dependent? How do notions of future, present and past figure in the understandings of time we conjure in this depiction? Whether we aim for some ideal structure in the future as does Habermas or focus more on rereading the present as does Gadamer we need to work at how we mediate past, present and future. In the context of practitioner oriented research we also need to concern ourselves with how we construct ourselves as future, present and past beings in this depiction. In this section we look at how narratives are constructed as accounts of the passing of time. We then connect this with the task of pinning down bits of experience faced by teachers carrying out reflective practitioner research where the person speaking sits inside the situation being described.

Our broader understandings of the flow of time, we suggest, are conditioned by the media through which we receive depictions of it (c.f. Derrida, 1994). Newspapers, for example, create as well as report news. They have considerable influence over the way in which information about the present is processed and the form it has to take to be heard. Such media channels are instrumental in our everyday construction of the world in which we live. They are part of the shorthand we all employ in coming to terms with the complexity we face. In research we are in the business of creating a similar mediating layer with many similar characteristics, and are susceptible to varying interpretations of its function. Research may be targeted at finding out how things are, how things work, or be about describing the world in some other way. But we are always confronted by the unanswerable question as to whether our language is responsive or assertive. As researchers, are we saying how things are or telling people how it should be seen? In constructing validity criteria for our assertions whose interests are we serving? In particular, for the remainder of this paper, what is reflected in reflective writing produced within practitioner research? We propose that we are more than passive recipients of our supposed mirror images. And that writing plays an instrumental role beyond mere reflection.

Within such research processes, how then do we build a sense of our own identity? For a teacher engaged in reflective research over a period of time pieces of writing often get created. In this sense these teachers can be seen as being responsible for creating their own identities, insofar as any statement predicates a perspective which provides a snapshot of how the researcher makes sense of a situation. Sometimes this also provides an explicit account of how they see themselves within this situation. Nevertheless, whilst some contemporary writers might claim that identity is an effect rather than an origin of linguistic practice, one's own identity can still be something one asserts and deploys rather than merely discovers. 
Identity should not be seen as a stable entity- something that people have- but as something that they use, to justify, explain and make sense of themselves in relation to other people, and to the contexts in which they operate. In other words, identity is a form of argument. As such it is both practical and theoretical. It is also inescapably moral: identity claims are inevitably bound up with justifications of conduct and belief (Maclure, 1993, p. 287, author's own emphasis).

We argue that this construction and use of identity by the researcher is not pinned down to a time and place. Rather it is a function of a rather more fluid reflective process. In this process practitioner researchers implicate themselves in the situations they describe. Further, narratives as generated from these reflective writings can form a layer that conditions the research situation from which they are generated. Yet these narratives are susceptible to on-going renewal as their relationships to the research situation which generated them are reevaluated.

Ricoeur (e.g. 1984) argues that the passage of time does not lend itself to being described as a sequence of events, features or stages but instead needs to be understood as being mediated by narrative accounts of such transitions, relying on interpretations which at a very basic level cannot be seen as comprising phenomenological features. Ricoeur's analysis begins with an account of Augustine's twelfth century work Confessions. Ricoeur (1984, p. 4) suggests that in Book 11 of this work Augustine "inquires into the nature of time without any apparent concern for grounding his inquiry in the narrative structure of the spiritual autobiography developed in the first nine books of the Confessions". He then follows this with a discussion of Aristotle's Poetics, written some 1500 years earlier, in which he "constructs his theory of dramatic plot without paying attention to the temporal implications of his analysis" (ibid). Ricoeur then combines these themes of the two works in his own thesis within which time and narrative are mutually constitutive whereby "time becomes human to the extent that it is articulated through narrative mode, and narrative attains its full meaning when it becomes a condition of temporal existence" (op cit, p. 52).

Following Aristotle he suggests Plot is the mimesis (imitation) of an action. We take this to mean that to imitate an action in words is to offer an interpretation of an event, in which some causal relationships might be postulated in the form of a plot. Such interpretations, however, can always be revisited. Although as Ricoeur frequently reiterates in his earlier work (e.g. Ricoeur, 1981) such interpretations are never final, although some may be closer to the truth than others. But in his later analysis Ricoeur (1984, p. xi) introduces three distinct senses to the term mimesis; namely

Mimesis 1: "a reference back to the familiar pre-understanding we have of the order of action"

Mimesis 2: "an entry into the realm of poetic composition"

Mimesis 3: "a new configuration by means of this poetic refiguring of the pre-understood order of action"

We understand these as follows: 
Mimesis 1 applies to our existing common sense view of the world in which we have gained experience of organising events in a particular way in making sense of the world. For example, if we show a video of an everyday classroom scene to a group of teachers in an in-service training session we might expect some commonality of interpretation.

Teachers will have developed some sense of how a classroom is organised and have some understanding of how different features are related (e.g. the teacher misjudged the level of work which led to some restlessness).

Mimesis 2 applies to unfamiliar situations in which normal ways of working are modified or disrupted through some sort of new initiative. For example, within many action research enquiries teacher researchers seek to try out new ways of characterising their professional practice and also new forms of actions are attempted as professional objectives are modified. Mimesis 2 can be seen as an experimental phase in which new ways of describing and new forms of actions are explored.

Mimesis 3 applies after the experimental phase has been assimilated into normal practice. Here past struggles have become dissipated as they lose their experimental edge with the new forms of practice that have been tried out becoming familiar components of everyday practice or otherwise consigned to the scrap heap of failed attempts.

Ricoeur places these phases under the umbrella of what he calls "semantic innovation". At the level of a sentence a new word or metaphor places stresses and strains on the existing words as they accommodate the new member. Ricoeur offers the example of "Nature is a temple where living pillars..." (op cit p. ix)). Here each word tugs at the conventional meaning of the others to produce a novel effect. The poetic or novel usage of certain terms takes them away from more mundane meanings towards a more expressive style that perhaps loses its charge with repeated use. Existing words holds on to meanings in a modified way and new words come to the fore in orienting our experience. At the level of narrative, new stories result in a reconfiguration of the way in which the world is experienced and acted in as older stories are repositioned.

\section{Narrative within practitioner research}

It seems to us that this style of analysis readily lends itself to a closer examination of how teachers engaged in reflective writing over a period of time construct their own notions of transition. In saying this we are making the assumption that this writing itself is a key instrument in renewing understandings of who one is and how one is. Nevertheless, at any point in time writing can provide a snapshot of an individual's concerns, her way of seeing things and the way in which she sees herself. Each piece of writing produced along the way within reflective practitioner research provides a caricature of particular concerns being addressed at different points in time, which reveal aspects of the story the researcher wants to tell of herself. Yet for most of us it is slightly embarrassing to look back at personal writings we produced a little while back and so our past gets accessed through the rather awkward medium of writings we now feel uncomfortable with. We can no longer quite connect with the issues as we saw them then, past tangles having been resolved with new ones entering present concerns. Past incidents and ways of life have 
been preserved as explanations. Brown (1996) discusses the creation of meaning within practitioner research as being analogous to how meaning arises within contemporary understandings of language (e.g. Saussure). He suggests that reflective practitioner produces a chain of pieces of writing over time and that meaning is derived from the succession of pieces of writing, where no individual piece has meaning in itself but rather depends on its relation to other pieces. The creation of meaning within a practitioner research enterprise can thus be seen as being dependent on the management of collected writings. The meaning of any story depends on its use in another story. However, we also wish to problematise how we understand the commencement of any research enterprise and suggest that we cannot easily define a starting point from which we can simply map out a possible future as a continuation of a singularly defined past. Events as depicted in any particular pieces of writing can always be revisited and reorganised in relation to each other in positing any newly supposed causal sequence.

In examining this sort of process we shall look at an example drawn from an enquiry carried out by one of the present authors (L). This was part of a programme of study for a research masters degree in which the work comprised three years of producing reflective writing examining aspects of her professional tasks. Her study spanned two successive work situations; as a teacher in Further Education and then as an access tutor at a University. The final dissertation comprised an account of the transition she experienced in her own professional functioning as an individual within various institutional settings. For much of her time on the programme L described herself in the role of someone experiencing difficulties as a result of people marginalising her contribution. Her work for the course aspired to the modernist plot of making things better, a would be "victory narrative" (Stronach \& Maclure, 1997) but within a Kafkaesque world of infinite deferral. The stories documented difficulties as successive conceptualisations of ways forward floundered. L's conception of community was one where she was situated as a participant on the fringes. It was this recognition that brought about a change in her approach. A sequence of extracts below, taken from her reflective journal but then reproduced in her dissertation (Roberts, 1997), provide a taste of this transition, in which successive pieces of writing produced over the course of the three years, according to specific concerns at the time of writing, are repositioned in new accounts of how the transition as a whole might be seen.

I have been experiencing some difficulty with one of the women students. I believe there is a personality clash which I feel affects the teaching/learning relationship. The situation has got me thinking about my interaction with individuals and groups in a classroom setting and how the dynamics can facilitate or impede learning. I am particularly intrigued by my role in this situation. (p. 13 1994)

I believed I could understand my practice - what was happening in the classroom - simply by focusing on myself and my interaction with students. I ignored other contextual features - my relationship with colleagues, the structure of the organisation and the wider social context. As far as I could see the issue was my classroom practice and nothing else was relevant. I needed to know why my methods were not having the impact I wanted 
with certain groups, therefore my focus should centre on the classroom and myself. (p. 12 1996)

It was ridiculous to say that I am not part of the world. My personal beliefs and values may be different but I am tied into the daily rituals and practices and this is recognised by those I came into contact with - hence the tensions I experience in those interactions ie I represent the institution. That is why I am able to speak with the institutional voice. Even though I may be at odds with certain practices or beliefs I adopt the rules of the organisation. (p. 58 1997)

When I review my experiences within the institution and account for the problems as being the result of institutional racism I am inscribing myself "as a subject in a particular symbolic chain whose signifier" is racism...I have positioned myself in a particular discourse and have taken the identity such a discourse allows... When I review my accounts of practice what is revealed is my sense of hierarchy and lack of control in the situation. The journal entries... provide some evidence of this. Use of passive tense removes all notion of actor. This gives a sense that the structures are some unseen force over our heads guiding our every move. I speak in terms of "the unit", "the project" and "the programme" as though they existed as concrete entities with the power of action. War-like - "bombarded', "firing", "barrage" reveal the extent to which I feel I am under attack. (1997)

This later style of writing however armed L for her own attack. It seemed that the very apparatus within a course designed to liberate gave rise to the frame which constituted her oppression. Her self reflection on practice conjured as a strategy for progress resulted in a particular version of self trapped within certain conceptions of practice and of potential conceptions of progress within them. Her attack took the form of resistance against the modernist conceptions of supposed emancipatory moves embedded in the course's own self image (to improve's one's teaching, to unfold the picture one tells, etc.). Her critical stance, of this "critical" strategy which had become part of her lived tradition, enabled her to distance herself from this. In doing this, she seemed, intentionally or otherwise, to be redefining her community as the course team and fellow students and succeeded in rattling the cage to make the course team feel uncomfortable about the assumptions underlying their own teaching strategies. L's examination of her own past writing revealed a pattern; stories formulated in this particular way always gave rise to a particular conception of herself. It revealed itself to be a caricature, a facade which itself needed to be rejected. Her study instead became an account of how such caricatures are produced as a consequence of particular conceptions of practitioner research.

Now in deploying Ricoeur's analytical frame how might we capture the transition being supposed here. Mimesis 1 might be seen as the first world L sees herself occupying where she is situated as weak, in a world resisting her attempts to impose some sort of modernist plot. Such accounts are derived from her everyday style of reflection on her practice, laced with the analytical approach developed within the course. Within this frame both her professional institutional setting and course structure were seen as non- 
negotiable. Only her actions could be changed. Mimesis 2 derives from her recognition that the style of story frame she uses is inhibiting. It feels as though she is always returning to the same frustrating starting point. Her stories are thus reevaluated and new ones are tried for size. Her recognition that she was speaking with the institutional voice rather than against it repositioned her with a resulting shift in the perspective revealed in her writing. Thus she developed a critical stance towards the course strategies whilst also changing her understanding of her relationship with her professional situation. Mimesis 3 is the calm attitude, almost detached from the former state, where she is knowingly living in the new realm where the new brand of stories are seen as fitting better to her new understanding of her professional role. The former stories have become mere history preserved as quotes of herself.

This account of L so far, however, was created by her tutor for the purposes of writing this paper. The tutor selected what he saw as four poignant extracts from L's final dissertation and spun a yarn around them consistent with the assertions he was making within the paper. We would however, as co-authors, like to distance ourselves from research traditions that deny data a right to reply. Fortunately L retains a live voice and has responded to the choice of extracts through which she has been characterised and to the story that has been built around them:

This brings to mind earlier discussions with my tutor where I did not recognise my intentions or myself as revealed in his interpretations of my writing. Although these particular extracts do capture the essence of my evolving thoughts as I sought to make sense of my world, they do not capture the full flavour of my position at the time of writing. I am struck by the strident character of an L going on the attack, "redefining her community" and "rattling the cage". This L appears self assured and quite deliberate in her actions. As I remember it when I wrote the dissertation these extracts were presented to tell the story of my transitional shifts as I saw it looking back to the past from the vantage point of the present. I was writing as someone trying to make sense of how I came to frame my experiences during the course of the research. Elements of this new story do resonate but this is no longer the story of my tortuous journey. But I am reminded of a quote I used in the dissertation: "There are no "final" stories but each story reflects our own way of organising and understanding the social world" (Jennings \& Graham, in Zuber-Skerritt, 1996, p. 169).

\section{Concluding comments}

Empathetic historical analyses (e.g. Collingwood, 1994) focus on understanding why the actor acted in the way s/he did. But then the actor might have been deluded, pursuing some unrealistic fantasy of what $\mathrm{s} /$ he wanted to achieve. So then where is history located; in the supposed truth then, the whole truth or nothing but the particular truth you have in mind right now. Ricoeur (1984) talks of fragmentary temporalities whereby temporality defies phenomenology except at the level of narrative. That is the process of history cannot be fully captured in the stories about it but instead we employ a form of phenomenological highlighting. In teacher education, for example, we mythologise certain expressions, points of references which become socially constructed phenomenologies which serve as anchorages for given communities (e.g. "levels of 
attainment", "failing schools", "reflective practice"). Official languages become an imposed form of anchorage which taints the space people see themselves working in. Developmental practitioner research is thus always conditioned by the discourses which surround it - sometimes pulling, sometimes pushing where any notion of an underlying truth is the myth that gets told at the time (Barthes, 1972).

What then is the main function of practitioner oriented educational research and how is it associated with revisions of practice? Within this paper we have sought to reconceptualise the task of the practitioner researcher. We have nudged away from Habermasian style victory narratives in which research is targeted at creating a better world, as conceptualised from specific interpretations of the present. We have also more cautiously rejected the "being as we are" stance of Gadamer. We would however, accept Elliott's defence of Gadamer insofar as it sees practical reflection both as a critical instrument of traditions and as a critical instrument of the perspectives from which those traditions are successively viewed. In line with Ricoeur, however, we claim that we need to focus on the key role of narrative in building an account of the passage of time and to understand research as a mechanism present within a process of change through which we distance and historicise ourselves. Ricoeur's analysis suggests that narratives might be seen as always imperfect accounts of time but of a time that depends on these very narratives. Thus, Ricoeur seems to give a higher status to narratives in the construction of time than does Gadamer. He also demonstrates the rather fine dividing line between historical and fictional constructions (Ricoeur, 1985). We have suggested however that narratives are always susceptible to reformulation. We cannot suppose any finality in the authorial construction of the events $\mathrm{s} /$ he describes nor in the position adopted in making this construction. Nevertheless the author may recognise this and be always on the look out for more captivating descriptions. This search however results in the object of the search being reconfigured and reconceptualised which invalidates past attempts by the (now changed) author at pinning down this (now changed) object. Research discourses inevitably create the analytical frames that we use, which in turn create the objects we research; objects that grow and evolve whether we acknowledge this growth or not. In this way these discourses reinvigorate and renew both object (the researched) and subject (the researcher) of research. As such research becomes the instrument through which we build and understand our practice, not to reach some higher plane of perfection, nor to be more in touch with where we are in life, but rather, to make explicit a reflective/constructive narrative layer that feeds whilst growing alongside the life it seeks to portray.

\section{ACKNOWLEDGEMENTS}

Aspects of the theoretical discussion in this paper were constructed within a project entitled Primary Student Teacher's Understanding of Mathematics and its Teaching, carried out by Tony Brown, Una Hanley, Olwen McNamara and Liz Jones (Brown et al, 1999), funded by the Economic and Social Research Council, United Kingdom, project number R000222409. The authors are grateful to the Council for this support. 


\section{REFERENCES}

BARTHES, R. (1972) Mythologies (London, Paladin).

BROWN, T. (1996) Creating data in practitioner research, Teaching and Teacher

Education, 12(3), 261-270.

BROWN, T., MCNAMARA, O., JONES, L. \& HANLEY, U. (1999) Primary Student

Teacher's Understanding of Mathematics and its Teaching, British Educational Researc h Journal, 25(3), 299-322.

CARR, W. \& KEMMIS, S. (1986) Becoming Critical, (London, Falmer).

COLLINGWOOD, R. (1994) The Idea of History (Oxford, OUP).

DERRIDA, J. (1994) The deconstruction of actuality,Radical Philosophy, 68, 28-41.

GADAMER. H-G. (1962) Truth and Method, (London, Sheed Ward).

GALLAGHER, S. (1992) Hermeneutics and Education (Albany, SUNY Press).

ELLIOTT, J. (1987) Educational theory, practical philosophy and action research, British

Journal of Educational Studies, vol. 35(2) 149-169.

ELLIOTT, J. (1993) The relationship between 'understanding' and 'developing'

teachers' thinking, in J. ELLIOTT (Ed.) Reconstructing Teacher Education, (London, Falmer).

HABERMAS, J. (1972) Knowledge and Human Interests, (London, Heinemann).

MACLURE, M. (1993) Mundane autobiography: some thoughts on self-talk in research contexts, British Journal of Sociology of Education 14, 373-384.

RICOEUR, P. (1981) Hermeneutics and the Human Sciences (Cambridge, Cambridge University Press).

RICOEUR, P. (1984) Time and Narrative, vol. 1, (Chicago University Press, Chicago). RICOEUR, P. (1985) Time and Narrative, vol. 2 (Chicago University Press, Chicago).

ROBERTS, L. (1997) Insider-Outsider Discourses: Self and Human Agency in

Educational Establishments, MA dissertation, Manchester Metropolitan University.

STRONACH, I. \& MACLURE, M. (1997) Educational Research Undone: The

Postmodern Embrace (Buckingham, Open University Press).

WALKERDINE, V. (1988) Mastery of Reason (London, Routledge).

ZIZEK, S. (1993) Tarrying with the Negative (Duke, Durham, USA).

ZUBER-SKERRITT, O. (Ed.) (1996) New Directions in Action Research (London, Falmer). 